\title{
EXAMINATION OF THE QUALITY OF THE MANUAL PRE-STERILIZATION PROCESSING OF DENTAL INSTRUMENTS USING BENZIDINE TEST
}

\author{
V. Stoeva ${ }^{1}$, A. Kevorkyan ${ }^{1}$, R. Raycheva ${ }^{2}$, V. Kondeva ${ }^{3}$ and Y. Stoilova ${ }^{1}$ \\ ${ }^{1}$ Department of Social Medicine and Public Health, Faculty of Public Health, \\ Medical University, Plovdiv, Bulgaria \\ ${ }^{2}$ Department of Epidemiology and Disaster Medicine, Faculty of Public Health, \\ Medical University, Plovdiv, Bulgaria \\ ${ }^{3}$ Department of Pediatric Dentistry, Faculty of Dental Medicine, Medical University, Plovdiv, Bulgaria
}

Summary. The risk of infections in dental practices has been attracting for decades the interest of researchers from all over the world. A serious problem related to the transmission of blood-borne viruses is the thorough removal of organic matter, and mainly blood, from dental instruments when performing manual pre-sterilization decontamination. Application of benzidine test to prove the presence of blood traces on large and small dental instruments prepared for sterilization for the purpose of assessing the quality of the manual pre-sterilization decontamination. A total of 485 benzidine tests had been performed on selected 205 large and 280 small dental instruments visibly contaminated with blood. Of the total of 485 tested samples, blood traces were found in $63(12.99 \pm 1.53 \%)$. In the group of large instruments, positive benzidine test was obtained in $7.80 \%$ compared to $16.78 \%$ in the small instruments with the difference being statistically significant $(p=0.003)$. All 63 positive samples were additionally processed using ultrasound. Blood traces were found in 8 instruments with all of the positive samples being obtained from the barbed broaches. The manual cleaning does not guarantee decontamination of the dental instruments unlike the ultrasonic cleaning where any blood traces are being completely removed from the large instruments. In terms of the small instruments, there are still blood traces present 
after the ultrasonic cleaning which requires for it to be combined with a suitable enzyme cleaner, and the barbed broaches, as a requirement, should be used on a disposable basis.

Key words: benzidine test, large and small dental instruments, manual pre-sterilization decontamination

\section{INTRODUCTION}

$\mathrm{T}$ he risk of infections in dental practices has been attracting for decades the interest of researchers from all over the world. Blood-borne pathogens such as hepatitis $B$ virus (HBV), human immunodeficiency virus (HIV) and hepatitis C virus (HCV) have been a formidable challenge to the medical community since their discovery. Medical science, based on evidence obtained through molecular epidemiology methods, provides irrefutable data on the transmission of these infections in the dental practice [1-7]. A serious problem related to the transmission of blood-borne viruses is the thorough removal of organic matter, and mainly blood, from dental instruments when performing manual pre-sterilization decontamination. In that regard, the employment of methods for controlling pre-sterilization preparation of instruments is crucial, especially when such preparation is being performed manually. One of the first methods globally introduced as early as 1904 designed to prove the presence of blood traces was the benzidine test initially employed by the forensic science [8] and later adopted in the medical practice. The aim of the study was to apply benzidine test to prove the presence of blood traces on large and small dental instruments prepared for sterilization for the purpose of assessing the quality of the manual pre-sterilization decontamination.

\section{MATERIAL AND METHODS}

A total of 485 benzidine tests had been performed in the period January-February 2015 on selected 205 large and 280 small dental instruments visibly contaminated with blood. The following algorithm was employed:

1) visibly blood-contaminated large and small instruments (large-mirror, probe, college tweezers, forceps; small - steel burs, barbed broaches, K-files, H-files) were soaked into disinfectant bath for 30 minutes. The disinfectant used had antibacterial, virusocidal (enveloped viruses), tuberculocidal and fungicidal action and contained alkylamine and $\mathrm{N}, \mathrm{N}$-didecyl-N-methyl-poly (oxyethyl) ammonium propionate as active ingredients;

2) instruments underwent mechanical manual cleaning using brush, then rinsing and drying. The brush used was disinfected upon task completion;

3) using a drop counter, 3 drops of benzidine solution were applied on the instruments. The test was considered valid and was reported as positive upon the for- 
mation of a characteristic blue coloration (from pale to intense blue) which indicated the presence of blood traces on the instruments;

4) instruments which yielded positive benzidine test result were subjected to mechanical cleaning using ultrasonic bath filled with disinfecting solution of the same disinfectant used for the initial processing of the instruments;

5) reapplication of the benzidine test.

The tests have been obtained in five dental practices in the city of Plovdiv, Bulgaria in the course of five visits. To visualize the blood traces, the benizdine test employed was based on benzidine's property to be oxidized by the hemoglobin in the blood. The benzidine solution was prepared according to the respective prescription (Benzidine Adler test) and was performed in three stages: Stage one - dissolution of dry benzidine $\left(\mathrm{NH}_{2} \mathrm{C}_{6} \mathrm{H}_{4} \mathrm{C}_{6} \mathrm{H}_{4} \mathrm{NH}_{2}\right)$ in glacial acetic acid. Two grams of benzidine are mixed with $50 \mathrm{ml}$ of acetic acid (solution A). Stage two - preparation of $3 \%$ solution of hydrogen peroxide (solution B). Stage three - mixing of solution A with solution $B$ in 1:2 ratio. Descriptive statistics, using proportions, was applied in order to provide a clear picture of observed data. Two-Sample z-test for the difference between proportions was used to prove statistical significance. Data was processed by IBM SPSS software package v.21.

\section{RESULTS}

Of the total of 485 tested samples obtained from large and small instruments, blood traces were found in $63(12.99 \pm 1.53 \%)$ which we consider to be a high relative share (fig. 1).

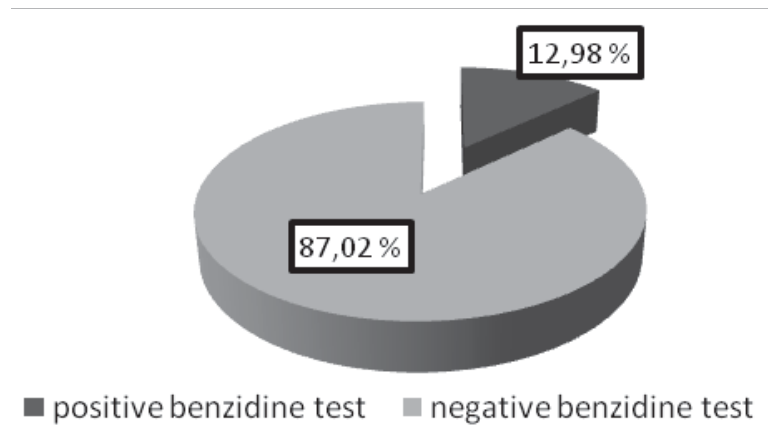

Fig. 1. Distribution of tested instruments based on the presence of blood established using benzidine test

In the group of large dental instruments, positive benzidine test was obtained in $7.80 \pm 1.87 \%(16 / 205)$ compared to $16.78 \pm 2.23 \%(47 / 280)$ in the small instruments with the difference being statistically significant $(z=2.90, p=0.003)$, (fig. 2). 

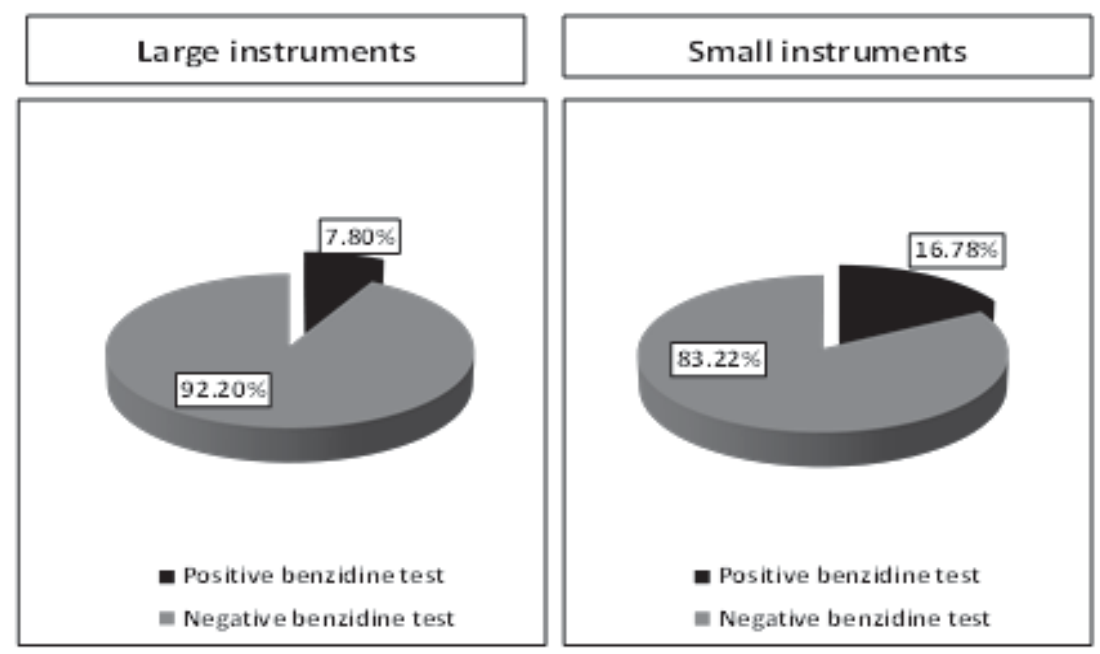

Fig. 2. Distribution of tested instruments in groups (large and small) based on the presence of blood established using benzidine test

Of the tested large dental instruments (table 1), only the probes were found to be free of blood presence. The college tweezers had the highest share of positive test results $-12.73 \pm 4.49 \%(7 / 55)$ with blood traces found in their serrated portion. In the other two large instrument types - forceps and mirrors the share of positive test results was $10.00 \pm 4.24 \%(5 / 50)$ and $8.00 \pm 3.84 \%(4 / 50)(z=0.34, p=0.726)$, respectively. The fact that microscopic blood traces were found even on the smooth surface of the mirrors is indicative of the serious flaws in the manual decontamination stemming out of the subjectivity in the course of its performance.

Data from the processing of 280 small instruments (table 1) show that the most problematic items in the manual decontamination are the barbed broaches with more than $1 / 4$ share of positive results $-16 / 60(26.67 \pm 5.71 \%)$. Poor results were also reported for the remainder of the small instruments - positive tests results from $12.86 \pm 4.00 \%(9 / 70)$ in the $\mathrm{H}$-files to $15.71 \pm 4.35 \%(11 / 70)$ in the K-files $(z=0.48, p=0.631)$ due to their design specifics. No significant differences in the share of positive benzidine tests were established upon comparing the results of the individual dental practices (fig. 3). This comes to show that the instances of oversight occurring during manual decontamination in the particular case share a common pattern and this points to the necessity to transition to alternative methods involving pre-processing with enzyme cleaners and ultrasonic cleaning with disinfectant and the best approach to validate the process - machine decontamination. 
Table 1. Distribution of the tested instruments based on the presence of blood traces per group and type for both processing procedures (manual decontamination and ultrasonic cleaning)

\begin{tabular}{|c|c|c|c|c|}
\hline \multirow[t]{2}{*}{ Instruments } & \multicolumn{2}{|c|}{$\begin{array}{l}\text { Manual decontamination } \\
\text { (Stage I) }\end{array}$} & \multicolumn{2}{|c|}{$\begin{array}{l}\text { Ultrasonic cleaning } \\
\text { (Stage II) }\end{array}$} \\
\hline & $\begin{array}{l}\text { total number } \\
\text { (n) }\end{array}$ & $\begin{array}{l}\text { positive } \\
\mathrm{n}(\% \pm \mathrm{SE})\end{array}$ & $\begin{array}{l}\text { total number } \\
\text { (n) }\end{array}$ & $\begin{array}{l}\text { positive } \\
\mathrm{n}(\% \pm \mathrm{SE})\end{array}$ \\
\hline \multicolumn{5}{|l|}{ large instruments } \\
\hline \multirow{4}{*}{$\begin{array}{l}\text { mirror } \\
\text { probe } \\
\text { college tweezers } \\
\text { forceps }\end{array}$} & 50 & $4(8.00 \pm 3.84)$ & 4 & 0 \\
\hline & 50 & 0 & 0 & 0 \\
\hline & 55 & $7(12.72 \pm 4.49)$ & 7 & 0 \\
\hline & 50 & $5(10.00 \pm 4.24)$ & 5 & 0 \\
\hline \multicolumn{5}{|l|}{ small instruments } \\
\hline \multirow{4}{*}{$\begin{array}{l}\text { barbed broaches } \\
\text { steel burs } \\
\text { K-files } \\
\text { H-files }\end{array}$} & 60 & $16(26.67 \pm 5.71)$ & 16 & $8(50.00 \pm 4.39)$ \\
\hline & 80 & $11(13.75 \pm 3.85)$ & 11 & 0 \\
\hline & 70 & $11(15.71 \pm 4.35)$ & 11 & 0 \\
\hline & 70 & $9(12.86 \pm 4.00)$ & 9 & 0 \\
\hline Total (n) & 485 & 63 & 63 & 8 \\
\hline
\end{tabular}

According to the algorithm presented by us, all 63 positive samples (16 from the large and 47 from the small instruments) were additionally processed using ultrasound (table 1). Blood traces were found in $12.70 \pm 4.19 \%(8 / 63)$ with all of the positive samples being obtained from the barbed broaches. The results confirm the need to adhere to the requirement for single-use of these items.

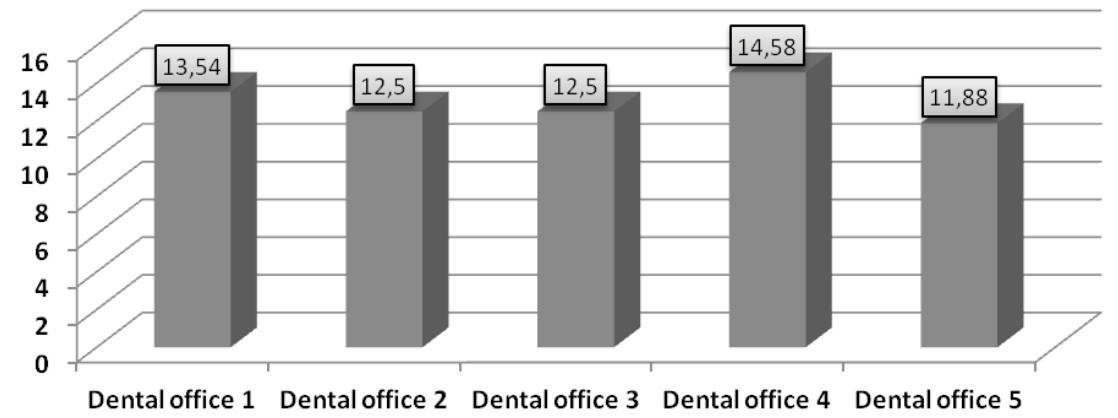

Fig. 3. Distribution of positive benzidine samples per dental practices (sampling locations)

\section{DISCUSSION}

Historically, in Bulgaria the manual pre-sterilization preparation of dental and other medical instruments has always been verified using benzidine testing [9]. 
According to data from the early years when this method for chemical control of the quality of cleaning of syringes and needles (these have been in use since the 80 's and are still being reused) and other medical instruments started to be used, the percentage of positive benzidine tests has remained steadily low $-3.68 \%$ in $1981,2.61 \%$ in 1982 and $2.43 \%$ in 1983 [10]. In that regard, it's worth mentioning the discussion of an analysis of results obtained in 1986 [9] according to which the low percentage of positive benzidine tests was probably due to the reduced total number of studies as a result of the introduction of disposable supplies, yet from an epidemiology perspective the most significant conclusion is that there is an insufficient number of studies covering risk units such as clinical laboratories and dental wards. This has been confirmed after 1990 by the opening of private medical and dental centers and practices at which time there occurred a significant increase in the positive benzidine tests which, on the one hand, is associated with the lack of knowledge of and non-compliance with the good practice of preparing instruments for sterilization, and, on the other hand, with the high number of scheduled checks by the supervisory bodies. A country-wide study of risk units (hemodialysis wards, clinical laboratories and dental practices) conducted in that period which tested a total of 665 samples from various objects from the external environment found a high level of microscopic blood traces $-24.4 \%$ (162/665) [11]. The authors found that the share of positive tests was highest in the dental practices, $27.9 \%(61 / 219)$, respectively, followed by that in the hemodialysis wards $-25.1 \%(65 / 259)$, with the lowest level being established in the clinical laboratories - 19.3\% (36/187), and based on the tested aids and instruments - the highest level $(29.3 \%)$ was found in the small dental instruments (burs, drains, square broaches, barbed broaches, handpieces). In contrast, a study using benzidine test which was carried out in a Hungarian hospital in the period 1995-2000 on a large number of surgical instruments showed that the percentage of positive tests had decreased over the years from $28.02 \%$ to $18.06 \%$ [12].

Over the years, in Bulgaria, in addition to the benzidine test, other methods for establishing blood traces have been used as well but none of them has been adopted in the long run due to flaws of various nature: hematest (in the form of strips to facilitate the work of the supervising bodies, used between 1990-2005), biuret method, use commenced in 2010 but was subsequently abandoned as it is inconvenient, flawed and expensive. Currently, the country's standard for prevention of nosocomial infections [13] stipulates the need to control the pre-sterilization preparation using qualitative and quantitative methods without specifying them. Thus, the benzidine test, despite the widely discussed flaws, remains the country's practice for quality control of the pre-sterilization manual decontamination. This test, along with its variations, continues to be used also in a number of former Soviet Union countries and is incorporated in teaching aids and regulatory documents [14, 15]. 
Tracing the Bulgarian historical record in that field is important because the effective epidemiology control eliminates the presence of blood on instruments already processed and prepared for sterilization as even tiny amounts of blood on the instruments could cause transmission of hepatitis B virus and, less frequently, of hepatitis $C$ virus and HIVIAIDS. This requires that dentists comply with the formal classification of dental instruments [16] as prepared and proposed by the experts depending on whether such instruments come into contact with blood or penetrate sterile tissues or cavities: - critical instruments (highest risk of transmitting infection) are those used to enter into or penetrate sterile tissues, cavities or blood stream (invasive or dental surgical procedures). These are: dental forceps and elevators, flap rake retractors, surgical burs, instruments used to place implants, implanted components such as mini-implants, surgical handpieces, etc.; - semi-critical instruments those contacting intact non-sterile mucous membrane or non-intact skin: dental mirror, instruments used for build-up, endodontic instruments, college tweezers, biopsy instruments and other non-critical instruments when used commonly in the mouth; - non-critical instruments (lowest risk) - contact with intact skin (protective goggles, facebows, dental bib clips, etc.).

The manual decontamination of dental instruments commonly conducted in Bulgaria poses numerous risks both for the patients and the dental team: it's timeconsuming; its performance involves subjectivity related to the knowledge and skills of the personnel; risk of occupational exposure to blood-borne viruses via percutaneous inoculation or spattering blood on the conjunctiva. It is only logical that the above flaws should lead to the abandonment of the manual decontamination, just as it has already been abandoned in many countries around the world. Our survey conducted in 2012 showed that only $64.8 \%$ of the dentist use barbed broaches on a disposable basis, i.e. more than a third put patients at risk [17]. According to the same survey, $82.7 \%$ state occupational risk exposure (cutting, pricking, etc.). This poses serious questions as to the good dental practice and the thorough decontamination of instruments. A cause for concern is that only $50 \%$ of the 162 surveyed individual dental practices use ultrasonic baths while globally this is one of the most widely-used and preferred method for cleaning instruments before sterilization. Top of Form В тази врътhe ultrasonic cleaning removes blood traces through a process called cavitation. In that process, waves of acoustic energy in an aqueous solution destroy the contamination on the surface of the instruments [18, 19], but its efficiency compared to the automated washing machines has long been put into question $[20,21]$. While manufacturers recommend that the cleaning solution should be replaced once daily, a study shows that the solution can get contaminated at each loading of instruments [22]. Moreover, ultrasonic cleaning requires time as well as a subsequent rinsing before sterilization. 
Today, the machine method for cleaning is considered the most effective and is the preferred one as it reduces the risk of exposure to blood spatters and lowers the risk of personnel injuries caused by sharp instruments and also eliminates the influence of subjectivity. We should also point that the most secure way to prevent the transmission of blood-borne infections is to use some of the instruments and protective clothing, etc, on a disposable basis.

\section{CONCLUSION}

The manual cleaning does not guarantee decontamination of the dental instruments unlike the ultrasonic cleaning where any blood traces are being completely removed from the large instruments. In terms of the small instruments, there are still blood traces present after the ultrasonic cleaning which requires for it to be combined with a suitable enzyme cleaner, and the barbed broaches, as a requirement, should be used on a disposable basis. The application of the bezidine test to control pre-sterilization processing of instruments must be replaced by modern methods recommended and used in other countries due to the established flaws such as toxicity, carcinogenicity, false positive results, etc.

Acknowledgments: This research was supported by Medical University of Plovdiv, Bulgaria (project № 1/2013).

\section{REFERENCES}

1. Hadler SC, Sorley DL, Acree KH, et al. An outbreak of hepatitis B in a dental practice. Ann Intern Med 1981;95 (2):133-8.

2. Shaw FE Jr, Barrett CL, Hamm R, et al. Lethal outbreak of hepatitis $B$ in a dental practice. JAMA 1986, 255 (23) :3260-3264.

3. Klein RS, Freeman K, Taylor PE, Stevens CE. Occupational risk for hepatitis $\mathrm{C}$ virus infection among New York City dentists. Lancet 1991; 338, No. 8782-8783, p1539-1542.

4. Blanchard A, Ferris S, Chamaret S, Guetard D, Montagnier L. Molecular evidence for nosocomial transmission of human immunodeficiency virus from a surgeon to one of his patients. J Virol 1998; 72:4537-40.

5. Bautista LE, Orostegui M. Dental care associated with an outbreak of HIV infection among dialysis patients. Rev Panam Salud Publica 1997; 2(3):194-20.

6. Cleveland JL, Lockwood SA, Gooch BF et al. Percutaneous injuries in dentistry: an observational study. J Am Dent Assoc 1995; 126(6):745-51.

7. Redd JT, Baumbach J, Kohn W, Nainan O, Khristova M, Williams I. Patient-to-patient transmission of hepatitis B virus associated with oral surgery. J Infect Dis 2007; 195 (9): 1311-4.

8. Garner DD, Cano KM, Peimer RS, Yeshion TE. An Evaluation of Tetramethylbenzidine as a Presumptive Test for Blood. Journal of Forensic Science 1976; 21 ( 4):816-821.

9. Avramova SG. Studies on receiving, physical-chemical properties, application and effectiveness of some disinfectants and sterilization control. PhD thesis, Sofia, Bulgaria, 1977. [In Bulgarian] 
10. Avramova SG, Dakova AG. Disinfection and sterilization in hospital. In: Andonov PS, editor. Nococomial Infections. Sofia: Medicine and gymnastics; 1986, p. 103-110. [In Bulgarian]

11. Dimitrova TT. Epidemiological studies on viral hepatitis B in high risk groups. PhD thesis, Sofia, Bulgaria, 1990. [In Bulgarian]

12. Filetoth Z. Hospital Acquired Infection-Causes and Control, 1st ed. Philadelphia: Whurr

13. Publishers Ltd; 2003, p.116-179.

14. Regulation № 3 from 8 May 2013 for approval of medical standard on prevention and control of nosocomial infections, issued by the Ministry of Health, promulgated in State Gazette №43, entry into force 11 May 2013. [In Bulgarian]

15. Sanitary rules № 2956a-83/ 28.12.1983 about devices, equipment, operation in outpatient dental settings, labor safety and staff hygiene, issued by Chief State Sanitary Doctor of the USSR. [In Russian]

16. http://zakon3.rada.gov.ua/laws/show/v2956400-83

17. Krivorova UI,Torgunakova AP, editors. General surgery. Kemerovo: State Medical Academy; 2008.

18. Australian Dental Association Guidelines for Infection Control. Second Edition, 2012.

19. Available at: http://www.ada.org.au/app_cmslib/media/lib/1203/m356702_v1_infection\%20control\%20guidelines\%202012.pdf

20. Stoeva VS, Kevorkyan AK, Raycheva RD, Aleksandrova M, Stoilova YD. Questionnaire study on theoretical and practical knowledge of nosocomial infections prevention and control in dental practice-Plovdiv, 2012. Nosocomial infections 2012, 9,(1-2), p.110-117. [in Bulgarian, English abstract]

21. Govoni M.Ultrasonic cleaning solutions: Are you getting the most from yours? Dental Economics 2011.Available at: http://www.dentaleconomics.com/articles/print/volume-101/issue-7/practice/ ultrasonic-cleaning-solutions-are-you-getting-the-most-from-yours.html

22. Center for diseases prevention and control (CDC) Guideline for Disinfection and Sterilization in Healthcare Facilities, 2008. Available at: www.cdc.gov/hicpac/Disinfection_Sterilization/5_0cleaning.html

23. Miller $\mathrm{CH}$, Tan CM, Beiswanger MA, Gaines DJ, Setcos JC, Palenik CJ. Cleaning dental instruments: Measuring the effectiveness of an instrument washer/disinfector. Am J Dent 2000; 13(1): 39-43.

24. Baxter RL, Baxter HC, Campbell GA et al., Quantitative analysis of residual protein contamination on reprocessed surgical instruments. J Hosp Infect. 2006; 63(4):439-444.

25. Burkhart NW, Crawford J. Critical steps in instrument cleaning: removing debris after sonification. J Am Dent Assoc. 1997; 128(4):456-63.

Corresponding author:
A. Kevorkyan
Department of Social Medicine and Public Health
Faculty of Public Health
Medical University
Bg - 4000 Plovdiv
e-mail: ani_kevorkian@mail.bg 